\title{
The logit model as a way of integral assessment of oxidative stress induced by mechanical eye injury
}

\author{
Olga Pavlova ${ }^{1, *}$, Olga Gulenko ${ }^{1}$, Konstantin Krupin $^{2}$, Victor Leonov ${ }^{3}$, and Svetlana \\ Palevskaya $^{4}$ \\ ${ }^{1}$ Samara State University of Railway Transport, st. Svobody, 2в, Samara, 443066, Russia \\ ${ }^{2}$ I.M. Sechenov First Moscow State Medical University (Sechenov University), st. Trubetskaya, 8 , \\ building 2, Moscow, 119991, Russian Federation \\ ${ }^{3}$ Private Institution Educational Organization of Higher Education "Medical University "Reaviz", \\ st. Chapaevskaya, 227, Samara, 443099, Russia \\ ${ }^{4}$ Samara State Medical University, st. Chapaevskaya 89, Samara, 443099, Russia
}

\begin{abstract}
The eyes are exposed to aggressive environmental influences. The blood-ophthalmic barrier is one of the resistance mechanisms serving to protect the body. Mechanical eye trauma violates the integrity of the hematoophthalmic barrier and induces oxidative stress on the background of general inflammatory process with cellular structures disturbances. The aim of our study was to investigate the peculiarities of free radical processes and antioxidant protection of the organism under induced oxidative stress by mechanical eye injury. The experiment was conducted on males of six months of age in an amount of 150. In blood, liver, brain, heart and skeletal muscle tissues we studied the state of enzyme indicators of oxidative stress in the dynamics in intact animals and in rats with violation of the blood-ophthalmic barrier by mechanical eye injury and different types of therapy. Based on the data obtained, we performed an integral assessment of oxidative homeostasis in injured animals using a logistic model. The resulting logistic regression equations allow modifying the redox processes in the body by applying biologically active compounds as additional therapy, but are of more fundamental than practical interest, as they illustrate the interrelationships of lipid peroxidation-antioxidant system enzymes in the tissues under study.
\end{abstract}

\section{Introduction}

The visual analyzer due to its structure is constantly exposed to aggressive environmental influences, primarily related to the spectral characteristics of sunlight, inducing increased formation of singlet oxygen forms, causing in turn the destruction of lipids, proteins, DNA cells [1-3]. The natural load on the visual analyzer is reinforced by insufficient nutrition, increased work intensity associated with increased exploitation of the visual organs, an

\footnotetext{
${ }^{1}$ Corresponding author: casiopeya13@mail.ru
} 
increasing proportion of chronic metabolic diseases associated with ophthalmic pathologies $[4,5]$.

The blood-ophthalmic barrier is one of the resistance mechanisms, serving to protect the body and prevent homeostasis disruption when the body is exposed to factors that can disrupt this balance. It is responsible for regulating the inflow into and out of the eye of various substances characteristic of normal and pathological metabolism, and also has an immune function, preventing the entry of microorganisms, antibodies and leukocytes $[6,7,8]$. Endothelial cells of the eye microcirculatory channel are the main element of the hemato-ophthalmic barrier and penetration of substances from blood into tissues and cells of the eye and back occurs through the dense cell membranes of the endothelium [9].

Mechanical trauma of the eye violates the integrity of the hematooophthalmic barrier and induces oxidative stress on the background of the general inflammatory process with disruption of cellular structures [10]. An additional factor aggravating this process is oxygen, which is necessary for cellular respiration. In the body there are always oxidative processes induced by free radicals and it is necessary for metabolism, respiration, immune reactions, but all this is balanced by repair processes thanks to endogenous and exogenous antioxidants [11, 12]. When inflammation increases the number of free radicals and oxidation processes exceed the reduction reactions, which leads to increased destruction of not only injured cellular structures, but the whole and this disrupts the normal activity of the entire body.

To determine the intensity of oxidative stress, we studied the activities of catalase, superoxide dismutase, glutathione peroxidase and glutathione reductase, as well as concentrations of malonic dialdehyde and diene con. gates in blood serum, liver tissue, brain, heart tissue and skeletal muscle tissue.

Catalase is the first link of intracellular protection against reactive oxygen species and its main function is the neutralization of the anion radical $\mathrm{O} 2-$, hydroxyl radical, radicals of unsaturated fatty acids (lipoperic acid), the splitting of hydrogen peroxide formed during cellular respiration into molecular oxygen and water.

Superoxide dismutase is an endogenous free oxygen radical acceptor, it removes superoxide radicals and prevents the formation of other more dangerous free radicals: hydroxyl radical and singlet oxygen.

Glutathione peroxidase catalyzes the peroxide detoxification reaction without free radical formation, using reduced glutathione, $\gamma$-glutamylcysteinylglycine (GSH), as a hydrogen donor.

Glutathione reductase together with glutathione peroxidase form a closed antiperoxidase complex in which peroxidase neutralizes peroxides to hydrogen and water, while glutathione is oxidized and glutathione reductase reduces oxidized glutathione, turning it into a substrate for glutathione peroxidase activity.

Malonic dialdehyde is one of the end products of lipid peroxidation, whose transformations result in the formation of insoluble lipid-protein complexes - lipofuscin.

Diene conjugates are the primary product of oxidation in the body and their concentration can be used to judge about the intensification of free-radical processes in the body. They are toxic metabolites that have a damaging effect on lipoproteins, proteins, enzymes and nucleic acids $[10,11]]$.

Thus, oxidative stress underlies the pathogenesis of many diseases, which emphasizes the importance of its assessment and finding ways to stop it $[13,14]$.

The aim of our study was to investigate the peculiarities of free radical processes and antioxidant protection of the organism under induced oxidative stress by mechanical eye injury.

The main objectives of our work: To study the state of oxidative stress indicator enzymes (catalase (CAT), superoxide dismutase (SOD), glutathione peroxidase (GP), 
glutathione reductase (GR), malonic dialdehyde (MDA) and diene conjugates (DC)) in dynamics in intact animals and rats with a violation of the blood-ophthalmic barrier by mechanical eye injury and conduct an integral assessment of oxidative homeostasis in injured animals using a logistic model.

\section{Materials and methods}

The experiment was carried out on male mongrel rats of six months of age, weighing 220$240 \mathrm{~g}$ and numbering 150 animals. All animals were divided equally into 5 groups of thirty rats in each group. Group 1 rats were intact animals. Groups 2, 3, 4, and 5 were experimental, where all animals received penetrating wounds to both eyes. Group 2 animals were not treated for mechanical eye injury. Group 3 rats received standard therapy for eye injury, Group 4 animals received standard therapy with the addition of quercetin injections intraperitoneally, and Group 5 animals received only quercetin injections. Detailed methodology of the experiment is presented in our previously published work. The animals during the experiment were kept with free access to water and food on a standard vivarium $\operatorname{diet}[15]$.

Activity of catalase, SOD, GP and GR, as well as concentrations of MDA and DC were studied in blood, brain tissues, heart tissues, liver tissues and skeletal muscle tissue before the experiment, as well as on 1, 3, 5, 7 and 14 days of the experiment. Activity of catalase was determined by M.A. Korolyuk method. SOD activity was determined by V.S. Gurevich method. Activity of GP was determined by the method of V.M. Moin. GR activity was determined by oxidized glutathione accumulation. MDA concentration was determined according to Rogozhin V.V. method. Determination of DC concentration was performed by spectrometric method [15].

In accordance with ethical standards, rats were decapitated under ether anesthesia, blood was collected and brain, heart, liver, skeletal muscle tissue were extracted and homogenates were prepared from them [15].

For an integral assessment of homeostasis in rats we used coefficients of oxidative stress: coefficient expressing the ratio of catalase activity to SOD activity; antioxidantoxidant index (AOI) expressing the ratio of catalase activity to MDA concentration; ratio of MDC concentration to DC concentration and local antioxidant index (LAI) representing the ratio of the product of catalase and SOD activity to MDA concentration.

\section{Results of the study}

During the processing of the experimental data we found that the most significant changes in the activity and concentration of the oxidative stress marker enzymes in the tissues under study occurred on the 5th, 7th and 14th days of the experiment, and we decided to write down the logistic regression equations for each tissue for the above time periods.

For the fifth day, the logistic regression equation $\mathrm{Y}=\mathrm{b} 0+\mathrm{b} 1 \times \mathrm{X} 1+\mathrm{b} 2 \times \mathrm{X} 2+\ldots \mathrm{Xi}+\mathrm{bi}$ for serum

$$
\begin{gathered}
\mathrm{Y}=-14.44+\mathrm{MDA} / \mathrm{DC} \times(-0.98)+\mathrm{CAT} / \mathrm{MDA} \times(-32.81)+\mathrm{CAT} / \mathrm{SOD} \times(-27.44)+\mathrm{LAI} \times 3.27 \\
+\mathrm{MDA} / \mathrm{G} \times(-0.54)+\mathrm{MDA} / \mathrm{CAT} \times 6.38+\mathrm{DC} / \mathrm{CAT} \times(-10.67),
\end{gathered}
$$

liver tissue

$$
\begin{gathered}
\mathrm{Y}=227.77+\mathrm{MDA} / \mathrm{DC} \times 20.30+\mathrm{CT} / \mathrm{CAD} \times 111.39+\mathrm{DC} / \mathrm{GP} \times(-10.21)+\mathrm{DC} / \mathrm{CAT} \times(- \\
325.94)+\mathrm{DC} / \mathrm{CAD} \times(-50.15),
\end{gathered}
$$


brain tissue

$$
\begin{gathered}
\mathrm{Y}=-32.88+\mathrm{MDA} / \mathrm{DC} \times 40.0+\mathrm{CAT} / \mathrm{MDA} \times(-27.0)+\mathrm{LAI} \times 2.43+\mathrm{MDA} / \mathrm{GR} \times(-44.67)+ \\
\mathrm{MDA} / \mathrm{GP} \times(-44.67)+\mathrm{MDA} / \mathrm{CAT} \times(-15.86)+\mathrm{MDA} / \mathrm{SOD} \times(-16.69),
\end{gathered}
$$

heart tissue

$$
\begin{gathered}
\mathrm{Y}=145.29+\mathrm{MDA} / \mathrm{DC} \times 11.95+\mathrm{CATH} / \mathrm{SOD} \times 55.94+\mathrm{DC} / \mathrm{GP} \times 51.64+\mathrm{DC} / \mathrm{GP} \times 3.53+ \\
\mathrm{DC} / \mathrm{CAT} \times(-76.19),
\end{gathered}
$$

skeletal muscle tissue

$$
\begin{aligned}
& \mathrm{Y}=0.25+\mathrm{MDA} / \mathrm{DC} \times 8.73+\mathrm{CAT} / \mathrm{CAT} \times 15.95+\mathrm{LAI} \times 0.71+\mathrm{MDA} / \mathrm{GR} \times 12.99 \\
& +\mathrm{MDA} / \mathrm{SOD} \times 7.05+\mathrm{DC} / \mathrm{GR} \times(-31.88)+\mathrm{DC} / \mathrm{GP} \times(-4.51)+\mathrm{DC} / \mathrm{SOD} \times(-22.53) .
\end{aligned}
$$

For the seventh day, the logistic regression equation $\mathrm{Y}=\mathrm{b} 0+\mathrm{b} 1 \times \mathrm{X} 1+\mathrm{b} 2 \times \mathrm{X} 2+\ldots \mathrm{Xi}+\mathrm{bi}$ for serum

$$
\begin{gathered}
\mathrm{Y}=-16.47+\mathrm{MDA} / \mathrm{DC} \times(-0.1)+\mathrm{CAT} / \mathrm{SOD} \times(-31.53)+\mathrm{LAI} \times 4,36+\mathrm{MDA} / \mathrm{GR} \times \\
\times(-5.56)+\mathrm{MDA} / \mathrm{GP} \times(-1.26)+\mathrm{MDA} / \mathrm{CAT} \times 17.45+\mathrm{DC} / \mathrm{CAT} \times(-13.54)+\mathrm{CAT} / \mathrm{MDA} \times(- \\
21.71),
\end{gathered}
$$

liver tissue

$$
\begin{gathered}
\mathrm{Y}=479.53+\mathrm{MDA} / \mathrm{DC} \times(-151.04)+\mathrm{CAT} / \mathrm{CAT} \times 131.92+\mathrm{MDA} / \mathrm{GP} \times(-390.00) \\
+\mathrm{MDA} / \mathrm{GP} \times(-44.68)+\mathrm{DC} / \mathrm{GP} \times(-78.54)+\mathrm{DC} / \mathrm{SOD} \times(-390.16)+\mathrm{DC} / \mathrm{GP} \times(-565.84),
\end{gathered}
$$

brain tissue

$$
\begin{gathered}
\mathrm{Y}=240.24+\mathrm{DC} / \mathrm{GP} \times(-109.39)+\mathrm{DC} / \mathrm{CAT} \times(-20.20)+\mathrm{DC} / \mathrm{SOD} \times(-37.70)+\mathrm{DC} / \mathrm{GP} \times(- \\
18.09),
\end{gathered}
$$

heart tissue

$$
\begin{gathered}
\mathrm{Y}=145.80+\mathrm{MDA} / \mathrm{DC} \times(-2.40)+\mathrm{CAT} / \mathrm{SO} \times(55.39)+\mathrm{MDA} / \mathrm{GR} \times(-24.61)+ \\
\mathrm{DC} / \mathrm{CAT} \times(-54.34)+\mathrm{DC} / \mathrm{SOD} \times 71.26
\end{gathered}
$$

skeletal muscle tissue

$$
\begin{aligned}
\mathrm{Y}= & -1.31+\mathrm{MDA} / \mathrm{DC} \times(6.65)+\mathrm{CAT} / \mathrm{MDA} \times(-29.72)+\mathrm{CAT} / \mathrm{SOD} \times 4.31+\mathrm{LAI} \times 1.58+ \\
& \mathrm{MDA} / \mathrm{G} \times 15.27+\mathrm{MDA} / \mathrm{CAT} \times 5.47+\mathrm{MDA} / \mathrm{SOD} \times 7.47+\mathrm{DC} / \mathrm{CAT} \times(-34.65) .
\end{aligned}
$$

For the fourteenth day, the logistic regression equation $\mathrm{Y}=\mathrm{b} 0+\mathrm{b} 1 \times \mathrm{X} 1+\mathrm{b} 2 \times \mathrm{X} 2+\ldots \mathrm{Xi}+\mathrm{bi}$ for serum

$$
\begin{gathered}
\mathrm{Y}=233.59+\mathrm{CT} / \mathrm{DS} \times(-197.22)+\mathrm{MDA} / \mathrm{G} \times 34.93+\mathrm{MDA} / \mathrm{DS} \times 102.31+\mathrm{DC} / \mathrm{GP} \times 140.58+ \\
\mathrm{DC} / \mathrm{DS} \times(-128.48),
\end{gathered}
$$

liver tissue

$$
\begin{aligned}
\mathrm{Y}=-30.13+ & \mathrm{MDA} / \mathrm{DC} \times 576.18+\mathrm{CAT} / \mathrm{SOD} \times 251.57+\mathrm{MDA} / \mathrm{GR} \times(-1900.75) \\
& +\mathrm{MDA} / \mathrm{GP} \times(-184.14)+\mathrm{MDA} / \mathrm{SOD} \times(-880.45)
\end{aligned}
$$

brain tissue 


$$
\begin{gathered}
\mathrm{Y}=-6.15+\mathrm{MDA} / \mathrm{DC} \times 271.48+\mathrm{CAT} / \mathrm{SOD} \times 345.42+\mathrm{MDA} / \mathrm{GR} \times(-592.55)+\mathrm{MDA} / \mathrm{GP} \times(- \\
134.93)+\mathrm{MDA} / \mathrm{SOD} \times(-287.88),
\end{gathered}
$$

heart tissue

$$
\mathrm{Y}=79.47+\mathrm{MDA} / \mathrm{DC} \times 11.30+\mathrm{CT} / \mathrm{CAD} \times 82.94+\mathrm{DC} / \mathrm{G} \times 165.81+\mathrm{DC} / \mathrm{CAT} \times(-127.46),
$$

skeletal muscle tissue

$$
\mathrm{Y}=-65.58+\mathrm{LAI} \times 0.60+\mathrm{DC} / \mathrm{GP} \times(-4.28)+\mathrm{DC} / \mathrm{CAT} \times(-61.49)+\mathrm{DC} / \mathrm{SOD} \times 48.34 .
$$

The logit-models obtained for each tissue under study allow predicting the shift of redox equilibrium in the rat organism by identifying and evaluating the most significant parameters of the organism's antioxidant status.

We also analyzed the dynamics of the number of coefficients in the logistic regression equations (Fig. 1).

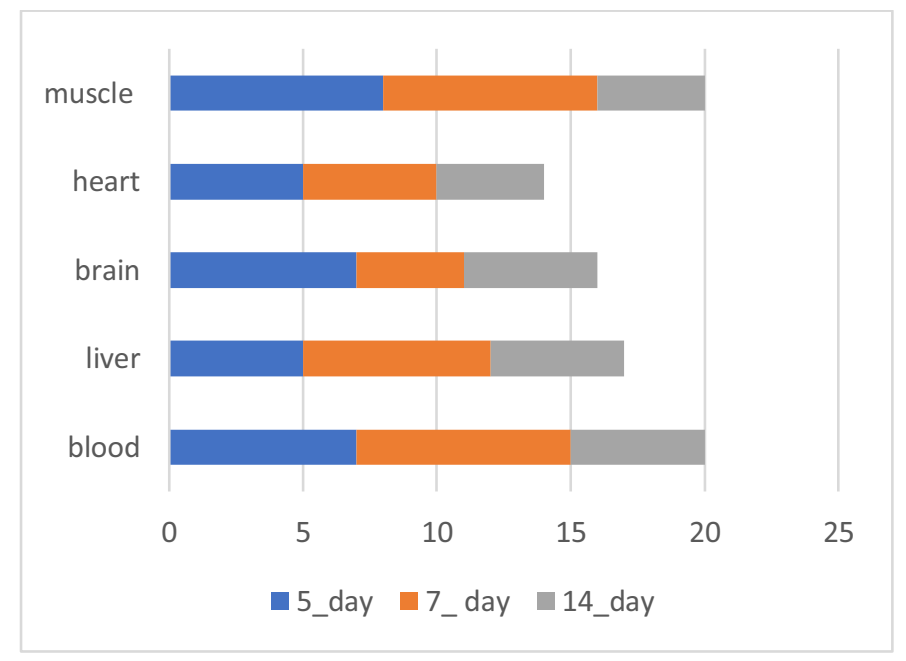

Fig. 1. Dynamics of the number of coefficients in the equations of logistic regression.

Mechanical trauma of the eye is a stimulant of oxidative processes in the body, as toxic products of autolysis of damaged tissues enter the blood and intensify oxidation and production of free radicals. This disturbs the redox equilibrium in the body, which is reflected in the state of lipid peroxidation system enzymes - antioxidants. At the same time, the activity of catalase, SOD, GP and GH decreases in tissues, but the concentration of MDA and DC increases. Tissues of brain, heart, liver and skeletal muscle tissue, as well as blood are no exception and react accordingly to mechanical trauma of the eye.

Application of different types of therapy simulates oxidative homeostasis of the tissues under study and calculation of indices allows to reveal insignificant fluctuations of the shaken redox equilibrium.

In general, the activities of lipid peroxidation-antioxidant enzymes in the studied rat tissues under oxidative stress caused by mechanical impact on the blood-ophthalmic barrier are more effectively stabilized by standard therapy of mechanical eye injury with the addition of quercetin as an injection.

Quercetin alone therapy for mechanical eye injury also affects enzyme dynamics in the tissues studied, promoting a return to physiological normality, but not as effectively as standard anti-inflammatory therapy alone or comprehensive therapy with quercetin supplementation. There is an opinion that the use of synthetic antioxidants to suppress 
oxidative stress can disrupt the signaling role of free radicals and thereby impair the body's adaptive capabilities.

From these considerations, it is clear that a systematic study of natural protectors with antioxidant properties such as a-tocopherol, ascorbic acid, carotenoids, flavonoids, ubiquinol, neuropeptides is an urgent task.

Analysis of the effects of these compounds on the body under conditions of oxidative stress, the mechanism of their effect and specificity of their protective effect can form the basis for improving treatment protocols for many human pathologies.

Natural antioxidants can play an essential role in the prevention of diseases associated with oxidative damage, and the study of the mechanisms of the antioxidant system creates an opportunity to develop a new strategy for the prevention and treatment of these diseases.

\section{Conclusions}

The resulting logistic regression equations for the identification of the most important factors of oxidative stress in mechanical eye trauma in the dynamics allow modifying the redox processes in the body by applying biologically active compounds as adjunctive therapy, but are of more fundamental than practical interest, as they illustrate the interrelation of lipid peroxidation-antioxidant system enzymes in the tissues under study.

\section{References}

1. Y.Z. Yuan, F. Yuan, Q.Y. Xu, J. Yu, L. Li, J.L. Zhang, Chinese J. Int. Med., 17 (4), 296-301 (2011)

2. D. V Dudok, I. Nagdee, K. Cheung, H. Liu, L. Vedovelli, E. Ghinelli, K. Kenyon, S. Parapuram, C.M. Hutnik, Clin. Exp. Ophthalmol., 43, 443-448 (2015), 10.1111/ceo. 12480

3. A.A.M. Torricelli, V. Singh, M.R. Santhiago, S.E. Wilson Investig. Ophthalmol. Vis. Sci., 54, 6390-6400 (2013), doi: 10.1167/iovs.13-12547. [PMC free article] [PubMed] [CrossRef] [Google Scholar]

4. N. Singh, M. Tiem, R. Watkins, Y.K. Cho, Y. Wang, T. Olsen, H. Uehara, C. Mamalis, L. Luo, Z. Oakey, B.K. Ambati, Blood., 121, $4242-4249$ (2013), doi: 10.1182/blood2012-08-453043. [PMC free article] [PubMed] [CrossRef] [Google Scholar]

5. V. Singh, V. Agrawal, M.R. Santhiago, S.E. Wilson, Exp. Eye Res., 98, 1-8 (2012), doi: 10.1016/j.exer.2012.03.006. [PMC free article] [PubMed] [CrossRef] [Google Scholar]

6. O. Roy, V.B. Leclerc, J.-M. Bourget, M. Thériault, S. Proulx, Investig. Ophthalmol. Vis. Sci., 56, 1228-1237 (2015), doi: 10.1167/iovs.14-16166. [PubMed] [CrossRef] [Google Scholar]

7. N. Okumura, S. Kinoshita, N. Koizumi, Cornea, 33, S37-S41 (2014), doi: 10.1097/ICO.0000000000000229. [PubMed] [CrossRef] [Google Scholar]

8. K.-Y. Han, J.A. Tran, J.-H. Chang, D.T. Azar, J.D. Zieske, Sci. Rep., 7, 40548 (2017), doi: 10.1038/srep40548. [PMC free article] [PubMed] [CrossRef] [Google Scholar]

9. A. Lozhkin, J. Mol. Cell. Cardiol., 102, 10-21 (2017)

10. M.A. Stepp, J.D. Zieske, V. Trinkaus-Randall, B.M. Kyne, S. Pal-Ghosh, G. Tadvalkar, A. Pajoohesh-Ganji, Exp. Eye Res., 121, 178-193 (2014), doi: 10.1016/j.exer.2014.02.007. [PMC free article] [PubMed] [CrossRef]

11. N. Chaudhari, Frontiers in Cellular Neuroscience, 8, 165-172 (2014) 
12. A. Bignucolo, J. Biotechnol., 167 (3), 309-315 (2013)

13. P.D. Ray, B.W. Huang, Y. Tsuji, Cell Signal., 24 (5), 981-990 (2012)

14. H. Sies, C. Berndt, D.P. Jones, Annu. Rev. Biochem., 86, 715-748 (2017)

15. A. Devyatkin, O. Pavlova, O. Gulenko, P. Boriskin, E3S Web Conf., 210, 06013 (2020), https://doi.org/10.1051/e3sconf/202021006013 